\title{
Flower visitors of lettuce under field and enclosure conditions
}

\author{
Masashi GoUBARA $^{1, *}$ and Takeshi TAKASAKI ${ }^{2}$ \\ ${ }^{1}$ The United Graduate School of Agricultural Science, Tottori University; Tottori 680-8553, Japan \\ ${ }^{2}$ Department of Plant Resource Science, Faculty of Agriculture, Kobe University; Kobe 657-8501, Japan
}

(Received 17 January 2003; Accepted 5 August 2003)

\begin{abstract}
Insects visiting lettuce flowers were investigated under field and enclosure conditions. In a 4-year field survey, visitors of 11 species belonging to 3 orders were observed. Most species visiting the flowers were sweat bees (Hymenoptera; Halictidae). The frequency (total days of visitation to lettuce flower/total days of flight by the insect) of visitations by the sweat bee Lasioglossum villosulum trichopse was obviously higher at $65.5 \%$ than those of other insects. Honeybees were not observed on the lettuce flowers. In a 5-year survey under enclosure conditions, 10 of 17 bee species reared and a hoverfly were observed to visit the lettuce flowers. The highest frequency of visitation was shown by $L$. villosulum trichopse (59.4\%), followed by Andrena knuthi (19.2\%) and Osmia cornifrons (8.6\%). Most visitors were one-day foragers and classified as temporary nectar foragers and continual pollen (and nectar) gatherers. Continual nectar foraging was observed in only 3 species, L. villosulum trichopse, An. knuthi and Ceratina boninensis. Daily flight activities of $L$. villosulum trichopse and the Lactuceae oligolectic bee An. knuthi corresponded to the morning blooming time of lettuce. The sweat bee L. villosulum trichopse may be a pollinator for hybrid seed production of lettuce.
\end{abstract}

Key words: Lactuca sativa; pollinator; Lasioglossum villosulum trichopse; Andrena knuthi; oligolectic

\section{INTRODUCTION}

Lettuce (Lactuca sativa L.) belongs to the Asteraceae family, sub-family Cichorioideae and tribe Lactuceae, and is one of the major vegetable crops in temperate areas of the world. Based on the morphological characteristics of lettuce, the cultivated forms can be classified into four types: Head type (var. capitata) (this type is generally subdivided into Crispheads and Butterheads), Romaine (Cos) type (var. longifolia), Leaf type (var. crispa) and Stem type (var. asparagina) (George, 1999). Lettuce has a cymose inflorescence that consists of many branches with an indeterminate number of flower heads (Soffer and Smith, 1974). Each flower head is composed of 15 to 25 ligulate perfect florets (Free, 1993). The lettuce flower opens in the early morning and remains open for only a short time. At that time, each stigma is very effectively pollinated by self-pollen pushed out from the anther tube by the brush hairs of the style leading to self-fertilization (Jones, 1927). Consequently, lettuce is an extraordinary vegetable crop not requiring an external method (wind or insect) of pollina- tion for seed production.

All lettuce cultivars are pure-line at present even though heterosis has been confirmed in the cross progeny of lettuce (Takada and Fujino, 1987; Langton et al., 1990) and a small quantity of $F_{1}$ hybrid seed production is possible through emasculation and hand pollination (Nagata, 1992). Most $F_{1}$ hybrid cultivars of vegetable crops are produced by self-incompatibility or male-sterility system. Malesterility can be utilized in $\mathrm{F}_{1}$ hybrid breeding procedures for self-fertilized plants. In lettuce and its progeny crossed with allied species, seven malesterile loci have already been identified (Lindqvist, 1960; Ryder, 1963, 1967, 1971) and male-sterile lettuce has also been recently produced through genetic engineering (Reynaerts et al., 1993). However, the commercial production of $\mathrm{F}_{1}$ hybrid lettuce seed using male-sterility has not yet been successful.

$F_{1}$ hybrid seeds are usually produced by insect pollination between two parental inbred lines. Flower visitors (=potential pollinators) which can transport the lettuce pollen grain efficiently, have not been found. This poses an obstacle for the

* To whom correspondence should be addressed at: E-mail: gomasashi@hotmail.com 
commercial production of $\mathrm{F}_{1}$ hybrid lettuce seed (Ryder, 1967; Reynaerts et al., 1993). Previous studies (as described below) on the pollinators of lettuce have been performed to recognize the danger of contamination of pure-lines by cross-pollination. Some insects have been reported as pollinators of lettuce flowers in the field including flies and two sweat bees (Agapostemon texanus and Halictus titusi=now classified to Lasioglossum titusi) in the western part of the USA (Jones, 1927), a sweat bee (Halictus zephyrus =Lasioglossum zephyrum) in the eastern part of the USA (Thompson, 1933), various species of hoverflies and a few butterflies in Britain (Watts, 1958) and thrips and solitary bees in the USA (Ryder, 1999). Under field conditions, cross-pollination resulting from visits by these insects has been reported in 2.02$3.04 \%$ (Thompson, 1933), 1.02-2.87\% (Thompson et al., 1958) and 0.15-11.52\% (Watts, 1958), but the degree of contribution of each insect is unknown. The honeybee Apis mellifera and the bumblebee Bombus spp. used for $\mathrm{F}_{1}$ hybrid seed production of commercial vegetables at present are rarely observed on the lettuce flower (Watts, 1958). To produce $F_{1}$ hybrid lettuce seed, it is essential to determine what novel pollinators visit the malesterile lettuce flower which produces the only nectar available for pollinators.

In particular crops for which the honeybee makes a rare or expensive contribution to pollination, there have been numerous studies to determine alternative pollinator insects, for example, mason bees Osmia cornifrons and O. lignaria propinqua for apples, an alkali bee Nomia melanderi and a leafcutting bee Megachile rotundata for alfalfa, and bumblebees Bombus spp. for tomatoes and red clover (Delaplane and Mayer, 2000; Westerkamp and Gottsberger, 2000; Bosch and Kemp, 2002). These bees showing definite flower preference for target crops have been established as efficient and practical pollinators. Furthermore, their application has been expanded to other crops beside the original target (Delaplane and Mayer, 2000). A novel pollinator must have a high preference for the flowers of the target plant. Oligolectic (pollen specialist) bees specially adapted to their host (pollen resource) plant show a high flower preference (Wcislo and Cane, 1996) and pollinate their host plants effectively (Cane and Payne, 1988; Ashman and Stanton, 1991; Schlindwein and
Wittmann, 1997). If an oligolectic bee on Lactuceae plants were to be discovered in lettuce, that bee may have excellent potential as a pollinator.

In the present study, we reared insects in the field and under enclosure conditions where lettuce cultivars and many other Lactuceae plants were cultivated and surveyed insects visiting the lettuce flowers to find potential pollinators for hybrid lettuce seed production.

\section{MATERIALS AND METHODS}

Cultivated plants. All studies were carried out under field and enclosure conditions in an experimental field (195 m altitude) at the Research Institute of Seed Production Co., Ltd., Sendai, Northern Japan. This field (including an investigation area of c. $300 \mathrm{~m}^{2}$ ) was open land where blooming plants were rare before 1993. After 1994, many kinds of blooming plants preferred by insect pollinators were cultivated in 24.0 or $24.5 \mathrm{~cm}$ plastic pots. The major plants cultivated were as follows: Brassica spp. (Seasonal anthesis: April to May), Potentilla spp. (April to August), Centaurea spp. (May to July), Anchusa officinalis (May to August), Daucus carota var. sativa (June to August), Agastache foeniculum (July to September), Lythrum spp. (July to September) and Origanum vulgare (July to October). The plants in more than 1,500 pots were blooming in the midsummer season when various pollinator insects were most frequently visiting flowers.

To attract pollinator insects which prefer the lettuce flower, half of the cultivated plants were changed to lettuce cultivars and related plants for six years from 1995 to 2000 (Table 1). We cultivated 18 lettuce cultivars (male-fertile, pure-lines) of 5 types: Crisphead type, i.e. 'V', 'Getto', 'New Salinas', 'Great Lake 366', 'Fresh World'; Butterhead type, i.e. 'Lisbon', 'Santa Clara', 'Buttercrunch', 'Red Boston'; Leaf type, i.e. 'Tima Santyu', 'Green Wave', 'Black Seeded Simpson', 'Oakleaf', 'Bonjour No. 2', 'Red Fire', 'Summer Red'; Romaine type, i.e. 'Cos Lettuce'; and Stem type, i.e. 'Stem Lettuce'. We also cultivated six major plants belonging to the tribe Lactuceae: Taraxacum spp. (April to May), Ixeris spp. (May to June), Picris hieracioides subsp. japonica (May to July), Hypochaeris radicata (May to October), Cichorium spp. (June to September) and Lactuca 
Table 1. Observation period, lettuce cultivars and number of lettuce plants which bloomed

\begin{tabular}{|c|c|c|c|c|c|c|c|c|}
\hline \multirow{2}{*}{ Condition } & \multirow{2}{*}{ Year } & \multicolumn{3}{|c|}{ Observation period } & \multirow{2}{*}{ No. of lettuce cultivars ${ }^{\mathrm{a}}$} & \multicolumn{3}{|c|}{ No. of lettuce plants blooming } \\
\hline & & First & Last & Days & & Min. & Max. & Mean $\pm \mathrm{SE}$ \\
\hline \multirow[t]{4}{*}{ Field } & 1997 & $7 / 17$ & $9 / 30$ & 52 & $3: a, j, p$ & 1 & 68 & $30.3 \pm 2.6$ \\
\hline & 1998 & $7 / 1$ & $9 / 18$ & 55 & $6: h, j, 1, m, n, p$ & 1 & 226 & $110.2 \pm 9.5$ \\
\hline & 1999 & $6 / 19$ & $9 / 20$ & 63 & 16: a, c, d, e, f, g, h, i, j, k, l, m, n, o, p, q & 1 & 105 & $36.1 \pm 4.3$ \\
\hline & 2000 & $7 / 14$ & $9 / 19$ & 45 & $4: \mathrm{b}, \mathrm{j}, \mathrm{p}, \mathrm{r}$ & 3 & 85 & $32.9 \pm 3.0$ \\
\hline Green house & 1995 & $10 / 1$ & $10 / 9$ & 7 & 1: c & 14 & 14 & $14 \pm 0$ \\
\hline \multirow[t]{4}{*}{ Cage } & 1996 & $6 / 19$ & $10 / 11$ & 65 & 7: a, c, j, k, m, o, q & 1 & 35 & $14.4 \pm 1.3$ \\
\hline & 1997 & $7 / 10$ & $9 / 22$ & 52 & $2: \mathrm{a}, \mathrm{p}$ & 1 & 20 & $14.8 \pm 0.9$ \\
\hline & 1999 & $7 / 22$ & $9 / 30$ & 51 & 4: e, g, j, 1 & 1 & 48 & $24.3 \pm 1.7$ \\
\hline & 2000 & $6 / 13$ & $10 / 17$ & 70 & $4: \mathrm{b}, \mathrm{j}, \mathrm{p}, \mathrm{r}$ & 1 & 22 & $4.6 \pm 0.7$ \\
\hline
\end{tabular}

${ }^{a}$ Cultivars a: V, b: Getto, c: New Salinas, d: Great Lake 366, e: Fresh World, f: Lisbon, g: Santa Clara, h: Buttercrunch, i: Red Boston, j: Tima Santyu, k: Green Wave, 1: Black Seeded Simpson, m: Oakleaf, n: Bonjour No. 2, o: Red Fire, p: Summer Red, q: Cos Lettuce, r: Stem Lettuce.

indica (August to October). Lettuce cultivars were sown in September or October so as to bloom from the next summer to early autumn and were cultivated in $24.0 \mathrm{~cm}$ plastic pots. For the experiment in 1995, only one cultivar, 'New Salinas', was sown in May 1995 and bloomed in September 1995. More than two lettuce cultivars of different types were used for the experiments after 1996 (Table 1).

The enclosure experiments were conducted in a greenhouse $(5.7 \times 13.3 \times 3.7 \mathrm{~m})$ in 1995 and in a cage $(7.0 \times 7.0 \times 3.5 \mathrm{~m})$ after 1996 . During the experimental periods, the greenhouse and the cages were filled with c. 200-370 pots containing the lettuce cultivars and other plants described above (Table 1).

Insects. To increase the density of insect visitors, twenty-one species of bees (Superfamily Apoidea) and a hoverfly Eristalis (12 insect species in the field and 18 in the enclosure conditions) were reared for this study (Table 2). These species of bees belonged to 10 genera: the yellow-faced bee Hylaeus, the sweat bees Halictus and Lasioglossum, the mining bee Andrena, the hairylegged mining bee Dasypoda, the megachilid bees Megachile and Osmia, the carpenter bees Ceratina and Xylocopa and the honeybee Apis.

The yellow-faced bee Hylaeus ikedai and the small carpenter bee Ceratina boninensis were introduced from the Bonin Islands, a subtropical area in Japan. The origin of the yellow-faced bee $H y$ laeus matsumurai, the leafcutting bee Megachile spissula and the large carpenter bee Xylocopa appendiculata circumvolans were populations of Shimane Prefecture, Western Japan. The yellowfaced bee Hylaeus nippon and the leafcutting bee Megachile sculpturalis were obtained from trapnests of the mason bee $O$. cornifrons set at various sites in Miyagi Prefecture. The hairy-legged mining bee Dasypoda japonica and the yellow-faced bee Hylaeus noomen were provided by Dr. N. Sugiura (Kumamoto Univ.). A colony of honeybee $A p$. mellifera, a type of disposable pollination unit 'Doredore 4000' with a queen and c. 4,200 workers, was purchased from Katakura Industries Co., Ltd., Japan. Other bees (all sweat bees, a mining bee Andrena knuthi, some leafcutting bees and carpenter bees) and the hoverfly Eristalis tenax were species native to our field.

To rear solitary bees, we prepared various types of nesting substrates: trap nests (holes in wood blocks, reeds, dead stems of plume poppy Macleaya cordata, glass tubes, etc.) for pre-existing hole-nesting bees (Hylaeus, Megachile, Osmia) (Krombein, 1967), bee-beds (wooden containers or plastic pots filled with clay soil) for ground-nesting bees (Halictus, Lasioglossum, Andrena, Dasypoda) (Miyanaga et al., 1999), dry twigs or stems of pithy plants (Rubus, Kerria, Lespedeza, Miscanthus, etc.) for the small carpenter bees Ceratina, artificial nest tubes for the small carpenter bees and the yellow-faced bees (Sakagami and Maeta, 1985) and dead twigs of various trees and dead stems of the plume poppy for the large carpenter bee Xylocopa. Each solitary bee was provided with 


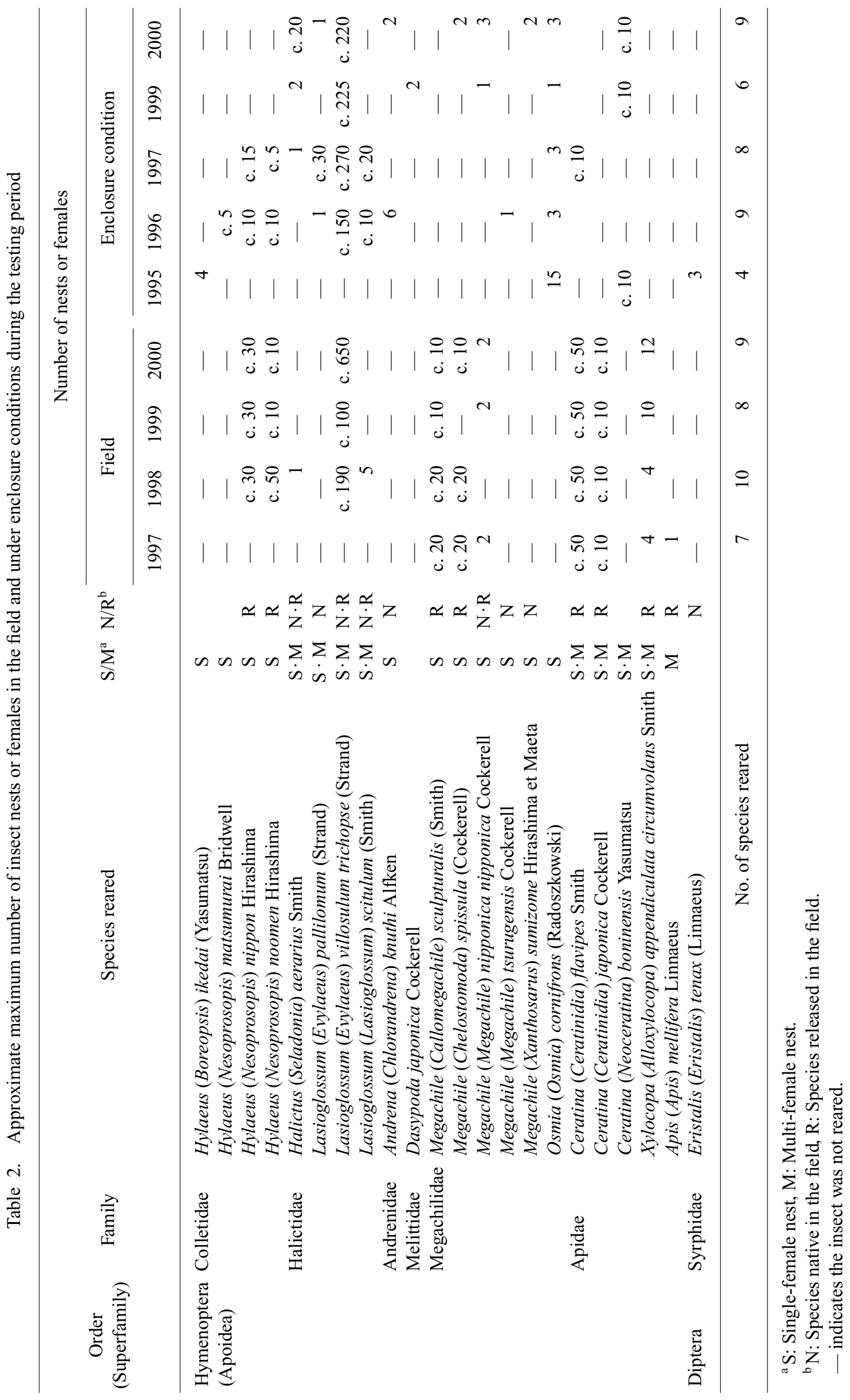


sufficient nesting substrates.

The nests of the bees could be prepared easily except in the case of the greenhouse in the autumn of 1995. Rearing experiments were done during the period of natural occurrence of most species. Only the mason bee $O$. cornifrons, which occurs in the spring season, was kept until summer or autumn through the overwintering state in a growth chamber at a temperature and humidity of $5^{\circ} \mathrm{C}$ and $75 \%$, respectively. The nesting sites of each bee were set at positions within 30 and $7 \mathrm{~m}$ from flowering lettuce pots in the field and in the enclosures, respectively. Each bee was reared under these conditions and the population size was frequently estimated by the number of nests or female bees. In the enclosures and in our field, pollen resources used by each bee were restricted. Bee overpopulation causes a lack of pollen resources which results in unusual foraging behavior of bees. To maintain normal foraging behavior of bees, a reduction of pollen grains on flowers were regularly checked early in the morning by macroscopic examination and the number of bees with high reproduction was adjusted by eliminating some nests.

Survey of insect visitors to lettuce. The insect visitors to the lettuce flower were surveyed in the greenhouse in 1995, in the cage after 1996 and in the field after 1997 (Table 1). In the field, some native insects besides reared species living at this study site were included in the survey. Total days of investigation covered more than half of the anthesis of the lettuce except in 1995 (Table 1). The surveys were conducted in the morning (usually starting between 7:30 and 9:30) when there was no rain. The observation time could not be fixed at a particular time because the blooming time (and the number of flower heads) of lettuce widely varied with the weather (Jones, 1927; Free, 1993). We searched for insect visitors on the lettuce while counting the number of flower heads. When insect visitors were found, the behavior of each insect was classified into four categories; temporary nectar foraging, continual nectar foraging, temporary pollen (and nectar) foraging and continual pollen (and nectar) gathering. Pollen foragers usually moved their legs rapidly to gather pollen. Nectar foragers extended their proboscis to drink the nectar and hardly moved their legs. Temporary foragers visited only a few flower heads and then flew away to seek other flowering plants. On the con- trary, continual foragers visited many flower heads to get food. Continual pollen gatherers were easily discriminated because of their flower constancy during a foraging trip and the specific characters (color and size) of pollen loaded on the scopa (hairs for carrying pollen).

After the survey on the lettuce flowers, the insects flying activity was monitored on the potted blooming plants and the nesting sites. Especially in the ground nesting bees, all nests were marked by placing a numbered small flag near each nest entrance. Conditions of entrances (shape, size and color) were recorded every evening and/or morning to estimate the state of bee activity (see Sakagami, 1977). Based on these data and the weather conditions, activities of each bee are presented as the visitation frequency (total days of visitation to lettuce flower/total days of flight activity performed by the insect) for each insect as a visitation constancy for the lettuce. Fisher's exact probability test was applied to detect group differences using frequency data.

Investigation of the fauna of flower visitors in the field. To reveal the fauna of flower visitors that were active in our field during the blooming periods of the lettuce, the kinds of insect visitors for a total of 15 days between mid-June and late-September were investigated in 1999. The procedures of route census described by Sakagami et al. (1974) were modified to minimize the impact on the insects reared in our field. This survey was conducted 15 minutes in the morning (usually starting between 7:45 and 9:20). All flower visitors on the potted blooming plants were counted by insect species. The insects were captured only when the visitor was unidentifiable. The relative abundance (the number of visitors of individual species/the total number of visitors) was calculated.

Daily flying time of bees and blooming time of lettuce. The daily flying patterns of the reared insects and blooming time of the lettuce were investigated in the cage on 20 June 2000, a clear day with sunrise and sunset at 4:13 and 19:03, respectively. The minimum and maximum temperatures in the cage were 16.8 and $33.1^{\circ} \mathrm{C}$, respectively. Six solitary bees, An. knuthi, L. villosulum trichopse, $L$. pallilomum, $\mathrm{Ha}$. aerarius, $\mathrm{C}$. boninensis and $O$. cornifrons, were investigated. From 4:30, before the bees started to fly, until 18:30, when all the bees had stopped flying, the number of females of 
each species visiting the potted blooming plants (236 pots of 21 plant species in 7 families) were counted every half-hour. The blooming time of the lettuce was investigated for 5 flower heads of 2 plants of Crisphead lettuce 'Getto'. Each blooming flower was classified into five stages based on angle of the corolla; closed corolla (stage 0), slightly opened corolla (stage 1), intermediate stage between stages 1 and 3 (stage 2), 45-degree opening (stage $3=$ half open), intermediate stage between stages 3 and 5 (stage 4) and fully opened (stage 5). The number of blooming flowers at each stage was counted every half hour and average blooming stage was calculated.

\section{RESULTS}

\section{Reared insects}

Seven to 10 and 4 to 9 insect species were successfully reared each year in the field and under enclosure conditions, respectively (Table 2). Except for two insects, the hoverfly $E$. tenax with no nidificating habits and the hairy-legged mining bee $D$. japonica with only flight activity for a few days, all other bees showed nesting activities. Usually, the nests of bees increased one to several times each year and became the greatest in midsummer. The number of females did not always coincide with the number of nests in any of the social bees belonging to Halictidae and Apidae. The solitary sweat bee $L$. villosulum trichopse was a species native to our field and was a minority before 1994, but its numbers greatly increased from 1995. Besides the natural population, the number of reared females of this species emerging in the spring season was estimated to be 80 (1998), 20 (1999) and 300 (2000) in the field, and to be 10 (1996), 310 (1997), 10 (1999) and 180 (2000) in the cage. From spring to midsummer, the nests of this sweat bee had increased 2.2-5 times under field conditions and 0.9-20 times in the cage (see Table 2).

\section{Insect visitors}

A total of 19 insect species were observed to visit the lettuce flower in both the field and under enclosure conditions (Table 3). Besides these species, minute insects such as thrips with poor pollen transportation ability were sometimes observed, but were ignored.

In the field, nine bee species, the hoverfly $E$. tenax and the butterfly Parnara guttata guttata were observed on the lettuce flowers. Among these 9 bee species, seven, i.e. Halictus aerarius, Ha. tsingtouensis, Lasioglossum affine, L. baleicum, L. pallilomum, L. villosulum trichopse and L. occidens, were sweat bees. Out of the 12 species of reared bees, only three species, i.e. Ha. aerarius, $L$. villosulum trichopse and $X$. appendiculata circumvolans, visited the lettuce flowers. The number of species visiting the flowers varied each year; 4 in 1997, 8 in 1998, 2 in 1999 and 2 in 2000. Only the sweat bee L. villosulum trichopse was observed every year. New lettuce flowers bloomed day after day and each flower closed each day. Therefore, potential pollinators for hybrid seed production must possess the trait that they visit the lettuce every day. The sweat bee L. villosulum trichopse had the highest frequency of days of visitation (visitation frequency: 65.5\%). This tendency was observed even though the sweat bee was not reared in 1997. The visitation frequency of this bee for each year was $55.8 \%(=29$ observed days $/ 52$ active days, 1997$), \quad 76.4 \% \quad(=42 / 55, \quad 1998), \quad 50.0 \%$ $(=31 / 62,1999)$ and $80.0 \%(=36 / 45,2000)$. Eight other bee species, the hoverfly E. tenax and the butterfly $P$. guttata guttata were observed on the lettuce flowers for only 1-3 days. The European honeybee Ap. mellifera with strong flight ability flew toward the nearby mountains and was not observed on the lettuce flowers.

Among 17 species of insects reared under the enclosure conditions, ten bee species, i.e. $H y$. matsumurai, Hy. nippon, Hy. noomen, Ha. aerarius, L. villosulum trichopse, L. scitulum, An. knuthi, O. cornifrons, C. boninensis and C. flavipes, visited the lettuce flowers (Table 3). The numbers of visiting species were 1 (1995), 5 (1996), 3 (1997), 1 (1999) and 3 (2000). Of these 10 species, Hy. nippon, Hy. noomen, L. scitulum, An. knuthi and C. flavipes never visited the lettuce flowers in the field. The highest frequency of visitation in 1995 was $42.9 \%$ (=3/7 days) of the mason bee $O$. cornifrons. In 1996, between two visitors with the highest frequency, i.e. An. knuthi $(38.5 \%=5 / 13)$ and L. villosulum trichopse $(30.8 \%=20 / 65)$, the difference was not significant (Fisher's exact probability test, $p=0.764$ ). In 1997, 1999 and 2000, the visitation frequency was the highest for L. villosulum trichopse, $63.5 \% \quad(=33 / 52,1997), 86.3 \%$ $(=44 / 51,1999)$ and $57.1 \%(=40 / 70,2000)$, and 


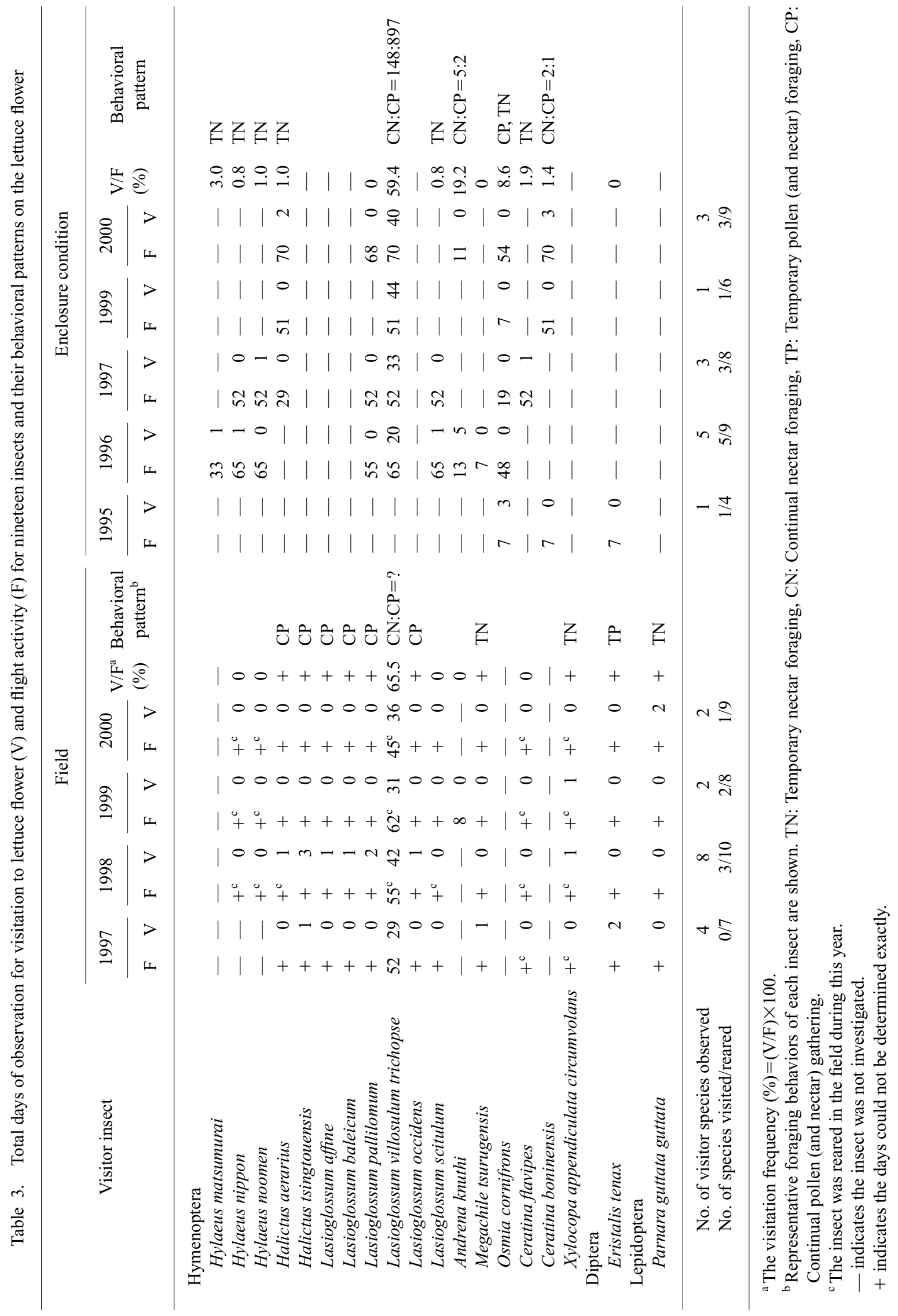


the differences from other visitors were significant (Fisher's exact probability test, $p<0.01$ ). The sweat bee $L$. villosulum trichopse showed a relatively high frequency of visitation with the average $( \pm \mathrm{SE})$ being $59.4 \%( \pm 11.4, N=4)$. The average visitation frequencies of $A n$. knuthi and $O$. cornifrons were $19.2 \%( \pm 19.2, N=2)$ and $8.6 \%$ $( \pm 8.6, N=5)$, respectively. However, their visitation frequencies greatly varied year to year. Other visitors were observed for only 1-3 days and their visitation frequencies were less than $5 \%$ even in the year of their observed visitation.

\section{Behavioral pattern of insect visitors}

Five sweat bees, Ha. tsingtouensis, L. affine, $L$. baleicum, L. pallilomum and L. occidens, behaved as continual pollen (and nectar) gatherers (Table 3 ). Three Hylaeus species, L. scitulum, M. tsurugenisis, C. Alavipes and P. guttata guttata, conducted only temporary nectar foraging. Most of these insects were one-day visitors. Continual nectar foraging behaviors were observed for only three species of bees, L. villosulum trichopse, An. knuthi and $C$. boninensis, and their frequencies (the total number of continual nectar foragers/the total number of foragers) in the enclosure were $16.5 \%(148 / 1,045$ foragers), $71.4 \%$ (5/7 foragers) and 66.7\% (2/3 foragers), respectively. Only the sweat bee $L$. villosulum trichopse behaved not only as a continual pollen (and nectar) gatherer but also as a continual nectar forager in the field.

\section{Fauna of flower visitors in the field}

In total 611 individuals belonging to 45 species of flower visitors (including 33 bees, 6 wasps, 1 butterfly and 5 flies) were observed in the morning during the blooming period of the lettuce. The investigation of the fauna of flower visitors showed that the most abundant flower visitor was $L$. villosulum trichopse (composition ratio: 49.4\%), followed by Apis cerana (9.8\%), L. pallilomum (3.4\%), Ceratina flavipes (2.8\%), Andrena japonica $(2.6 \%), X$. appendiculata circumvolans $(2.5 \%)$, Ha. aerarius $(2.3 \%)$ and Ha. tsingtouensis $(2.3 \%)$ (Fig. 1). The occurrence probability method (see Sakagami et al., 1974) showed that three species (L. villosulum trichopse, Apis cerana and $L$. pallilomum) were apparently dominant (defined as those of which lower confidence limit exceeds the vertical broken line, see Fig. 1) in our field.

\section{Pattern of flying activity of some solitary bees}

The flowers of the lettuce cultivar 'Getto' started to open after 5:30, had fully opened by $6: 30$ and had completely closed by 8:30 (Fig. 2). An. knuthi and $L$. villosulum trichopse started flying before 6:00 and showed a maximum flying activity between 7:00 and 7:30. Another sweat bee, L. pallilomum, began to fly after the blooming peak, then continued flight activities for more than two hours after the lettuce flower had closed. Two bee species, Ha. aerarius and C. boninensis, started to fly after the lettuce flower had closed. The mason bee $O$. cornifrons began to fly at 5:00 before the blooming time of the lettuce and kept flying until near sunset. The blooming time of the lettuce overlapped the flight activity of An. knuthi, L. villosulum trichopse and $O$. cornifrons bees which are

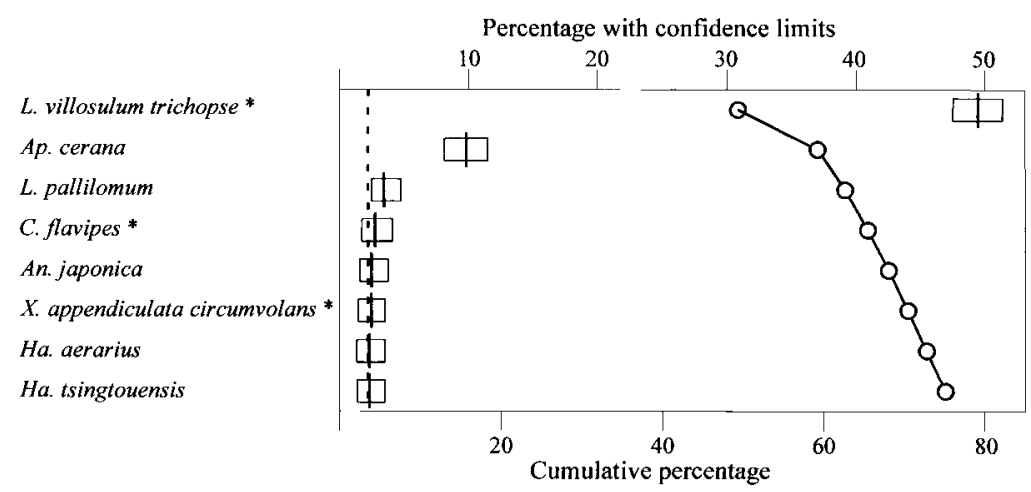

Fig. 1. Relative abundance of 8 predominant species in the field (1999) shown by occurrence probability method. Percentage (scale above) of each species is given by a short vertical line with each horizontal bar indicating confidence limits $(p=0.95$ for both upper and lower limits). Vertical broken line at left indicates the reciprocal of the number of species observed multiplied by 100 . Line connecting open circles indicates cumulative percentage ratio curve (scale bottom). Species name with an asterisk indicates the insect was reared in the field. 


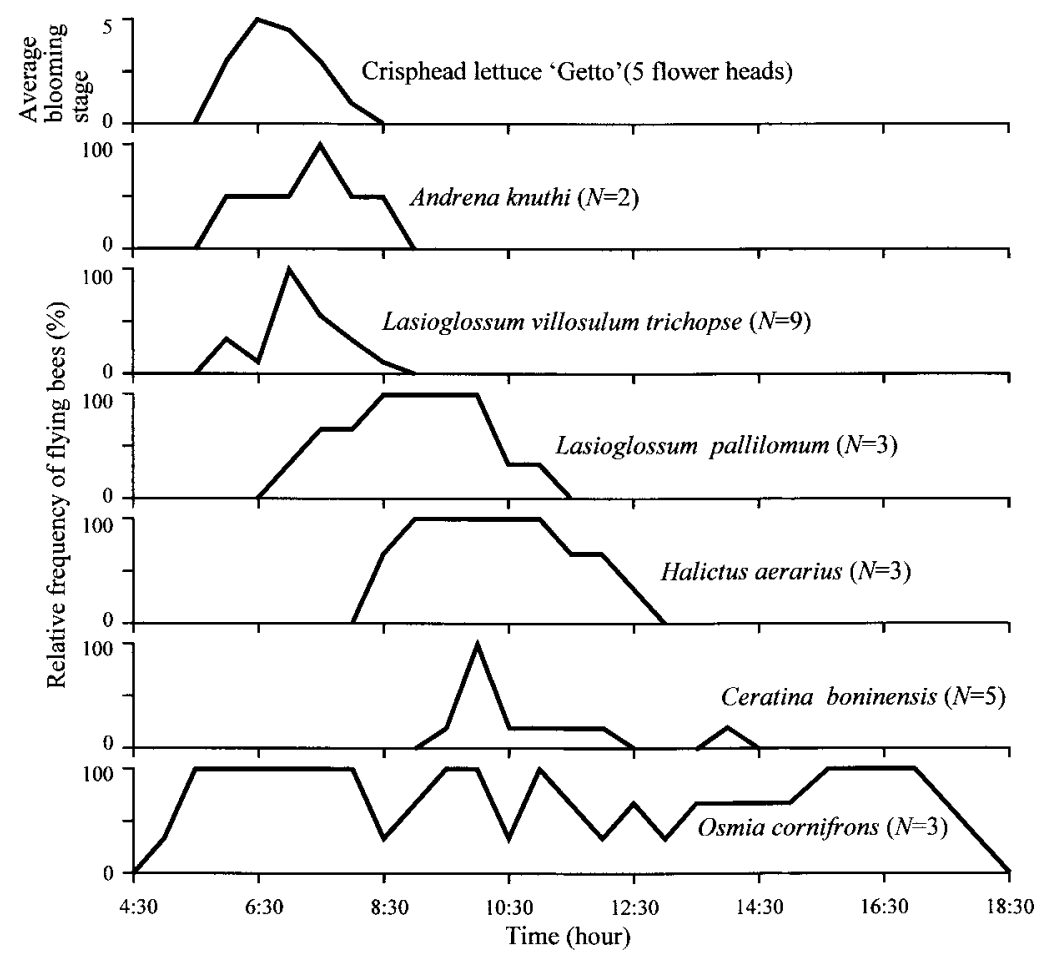

Fig. 2. Daily blooming time of the Crisphead lettuce 'Getto' and flight activity pattern of six solitary bees in a cage on 20 June 2000. Blooming flowers of lettuce were classified into five stages: closed corolla (stage 0), slightly opened corolla (stage 1), intermediate stage between stages 1 and 3 (stage 2), 45-degree opening (stage $3=$ half open), intermediate stage between stages 3 and 5 (stage 4) and fully opened (stage 5). The relative frequency of flying bees (\%) is calculated as the maximal number (=100\%) for each flying bee.

expected to be pollinators for lettuce.

\section{DISCUSSION}

Previous field studies indicate that only a few insects (mainly sweat bees or hoverflies) are observed on lettuce flowers (Jones, 1927; Thompson, 1933; Watts, 1958). In our field survey, eleven insect species containing seven species of sweat bees were observed on the lettuce flower, but most were one-day foragers and hardly ever selected lettuce on subsequent days (Table 3). Among the visitor insects, $L$. villosulum trichopse showed a distinctly high visitation frequency $(65.5 \%)$, which could not be explained by only the large number of $L$. villosulum trichopse reared because it showed a high frequency even when this sweat bee was not reared in 1997. No European honeybee Ap. mellifera with numerous workers visited the lettuce. Furthermore, the Japanese honeybee Ap. cerana, predominant species next to $L$. villosulum trichopse in the morning in the field (Fig. 1), did not visit the lettuce either. These findings suggest that very few insects act as effective pollinators of lettuce in the field.

Under enclosure conditions, the amount of flower resources available for insect visitors is restricted. Watts (1958) and Reynaerts et al. (1993) attempted to pollinate lettuce under enclosure conditions using hoverflies or bumblebees but were not successful. The European honeybee Ap. mellifera, the most familiar pollinator for fruit and vegetable crops, was also an inefficient pollinator for $F_{1}$ hybrid lettuce seed production under enclosure conditions (unpublished data). In our study, the sweat bee $L$. villosulum trichopse showed the highest visitation frequency $(59.4 \%)$ under enclosure conditions as well as in the field (Table 3 ). Following $L$. villosulum trichopse, the highest visitation frequencies were observed for An. knuthi and $O$. cornifrons at $19.2 \%$ and $8.6 \%$, respectively. These three bees may be useful as potential pollinators in an enclosed environment.

The daily blooming time of lettuce is one of the factors which influences the visitation frequency of insects. Flowering plants have flowering phenology (seasonal and daily anthesis) synchronized with 
specific pollinators to attract their activities and promote successful reproduction (Augspurger, 1981; Gross and Werner, 1983; Rathcke and Lacey, 1985). A species specific pattern of daily flying activity was observed (see Fig. 2), e.g., L. villosulum villosulum showed earlier and shorter daily provisioning time (Field, 1996). This pattern largely influenced by daily weather conditions rather than by seasons (unpublished data). The lettuce flower opens in the early morning and remains open for only about half an hour on warm bright days and for two hours on cool days (Free, 1993). In the enclosure with only lettuce, hoverflies died within $36 \mathrm{~h}$ and thus their use for pollination was unsuccessful (Watts, 1958), which may be due to the short blooming time of the lettuce. Insects with long daily flight activity such as $O$. cornifrons (Fig. 2) would be difficult to use as pollinators in enclosures where they could forage only on lettuce as their nectar resource.

Lactuceae plants (including lettuce) restrict the pollinators gathering of the floral reward by limiting the time of daily blooming. Oligolectic bees synchronize their flight activity with the seasonal and daily blooming of their host plant (Thorp, 1979). A total of 22 insect species including two Lactuceae oligolectic bees, An. knuthi and $D$. japonica were reared. These two lactuceae bees had few synchronous activities with the seasonal anthesis of the lettuce in northern Japan (data not shown), so few observations on the lettuce were possible. Daily flying activity of the Lactuceae oligolectic bee An. knuthi corresponded with the morning blooming time of the lettuce flowers (Fig. 2). However, these two Lactuceae bees showed a far lower visitation frequency than the sweat bee $L$. villosulum trichopse of which daily flying activity corresponded with the morning blooming time of lettuce flowers (Fig. 2).

Male-sterile lines may be used for the seed production of $F_{1}$ hybrid lettuce. The plants of malesterile lines never offer the reward of pollen to the pollinator, only nectar. A pollinator to be used for $\mathrm{F}_{1}$ hybrid seed production must possess the traits of continual nectar foraging and continual pollen gathering. Jones (1927) suggested that visitor bees of lettuce are only pollen collectors. In our study, 10 bee species among the 19 visitor species gathered pollen from lettuce flowers continuously (Table 3). However, continual nectar foraging was confirmed for only three species of these bees, i.e. L. villosulum trichopse, An. knuthi and C. boninensis, suggesting that possible pollinator insects are very restricted for lettuce seed production using male-sterile lines. L. villosulum trichopse frequently behaved as a continual pollen (and nectar) gatherer rather than a continual nectar forager. $L$. villosulum trichopse exhibited continual nectar foraging behavior on the flower of male-sterile lettuce (Goubara and Takasaki, in preparation). The sweat bee $L$. villosulum trichopse is most hopeful as a potential pollinator for $F_{1}$ hybrid seed production of lettuce in both the field and under enclosure conditions. Other bees, including honeybees and two Lactuceae oligolectic bees, have little potential as pollinators of lettuce.

\section{ACKNOWLEDGEMENTS}

The first author would like to express his thanks to Ms. Y. Inoue and Ms. M. Ohtsuki for their assistance in maintaining the blooming plants and in the rearing of bees. We are grateful to Dr. N. Sugiura for providing Dasypoda japonica and Hylaeus noomen. We are deeply indebted to Mr. T. Tsunoda, Mr. H. Horikoshi, Ms. Y. Tsuchiya and Ms. R. Ito (Kaneko Seed Co., Ltd.) for helpful advice. Special thanks are due to Dr. K. Hinata, Dr. K. Ojima, Dr. K. Hatakeyama, Dr. Y. Maeta and Mr. K. Gôkon for valuable discussions throughout this study. This research was supported by the Research Institute of Seed Production Co., Ltd., Sendai, Japan.

\section{REFERENCES}

Ashman, T.-L. and M. Stanton (1991) Seasonal variation in pollination dynamics of sexually dimorphic Sidalcea oregana spp. spicata (Malvaceae). Ecology 72: 9931003.

Augspurger, C. K. (1981) Reproductive synchrony of tropical plants: experimental studies on effects of pollinators and seed predators on Hybanthus prunifolius (Violaceae). Ecology 62: 776-788.

Bosch, J. and W. P. Kemp (2002) Developing and establishing bee species as crop pollinators: the example of Osmia spp. (Hymenoptera: Megachilidae) and fruit trees. Bull. Entomol. Res. 92: 3-16.

Cane, H. H. and J. A. Payne (1988) Foraging ecology of the bee Habropada laboriosa (Hymenoptera: Anthophoridae), an oligolege of blueberries (Ericaceae: Vaccinium) in the southeastern United States. Ann. Entomol. Soc. Am. 81: 419-427.

Delaplane, K. S. and Mayer, D. F. (2000) Crop Pollination by Bees. CABI, Wallingford, Oxfordshire. 344 pp.

Field, J. (1996) Patterns of provisioning and iteroparity in a solitary halictine bee, Lasioglossum (Evylaeus) fratellum (Perez), with notes on L. (E.) calceatum (Scop.) and $L$. (E.) villosulum (K.). Insectes Soc. 43: 167-182.

Free, J. B. (1993) Lactuca sativa L. In Insect Pollination of 
Crops. 2nd ed. Academic Press, London, pp. 161-163.

George, R. A. T. (1999) Compositae. In Vegetable Seed Production. 2nd ed. CABI, Wallingford, Oxfordshire, pp. 122-135.

Gross, R. S. and P. A. Werner (1983) Relationships among flowering phenology, insect visitors, and seed-set of individuals: Experimental studies on four co-occurring species of goldenrod (Solidago: Compositae). Ecol. Monogr. 53: 95-117.

Jones, H. A. (1927) Pollination and life history studies of lettuce (Lactuca sativa L.). Hilgardia 2: 425-479.

Krombein, K. V. (1967) Trap-nesting Wasps and Bees: Life Histories, Nests and Associates. Smithsonian Press, Washington, DC. 570 pp.

Langton, F. A., J. W. M. Smith and R. N. Edmondson (1990) Heterosis in crisphead lettuce (Lactuca sativa L.) hybrids. Euphytica 49: 15-23.

Lindqvist, K. (1960) Inheritance studies in lettuce. Hereditas 46: 387-470.

Miyanaga, R., Y. Maeta and S. F. Sakagami (1999) Geographical variation of sociality and size-linked color patterns in Lasioglossum (Evylaeus) apristum (Vachal) in Japan (Hymenoptera, Halictidae). Insectes Soc. 46: 224-232.

Nagata, R. T. (1992) Clip-and-wash methods of emasculation for lettuce. HortScience 27: 907-908.

Rathcke, B. J. and E. P. Lacey (1985) Phenological patterns of terrestrial plants. Annu. Rev. Ecol. Syst. 16: 179-214.

Reynaerts, A., H. Van de Wiele, G. De Setter and J. Janssens (1993) Engineered genes for fertility control and their application in hybrid seed production. Sci. Hort. 55: 125-139.

Ryder, E. J. (1963) An epistatically controlled pollen sterile in lettuce (Lactuca sativa L.). Proc. Am. Soc. Hort. Sci. 83: 585-595.

Ryder, E. J. (1967) A recessive male sterility gene in lettuce (Lactuca sativa L.). Proc. Am. Soc. Hort. Sci. 91: 366-368.

Ryder, E. J. (1971) Genetic studies in lettuce (Lactuca sativa L.). J. Am. Soc. Hort. Sci. 96: 826-828.

Ryder, E. J. (1999) Lettuce, Endive and Chicory. Crop Pro- duction Science in Horticulture, 7. CABI, Wallingford. Oxfordshire. 208 pp.

Sakagami, S. F. (1977) Seasonal change of nest survival and related aspects in an aggregation of Lasioglossum duplex (Dalla Torre), a eusocial halictine bee (Hymenoptera: Halictidae). Res. Popul. Ecol. 19: 69-86.

Sakagami, S. F., H. Fukuda and H. Kawano (1974) Biofaunistic survey of wild bees: problems and methods, with results taken at Mt. Moiwa, Sapporo. Materials $f$. Biol. Educ. 9: 1-60 (in Japanese).

Sakagami, S. F. and Y. Maeta (1985) Multifemale nests and rudimentary castes in the normally solitary bee Ceratina japonica (Hymenoptera: Xylocopinae). J. Kansas Entomol. Soc. 57: 639-656.

Schlindwein, C. and D. Wittmann (1997) Stamen movements in flowers of Opuntia (Cactaceae) favour oligolectic pollinators. Plant Syst. Evol. 204: 179-193.

Soffer, H. and O. E. Smith (1974) Studies on lettuce seed quality: III. Relationships between flowering pattern, seed yield, and seed quality. J. Am. Soc. Hort. Sci. 99: 114-117.

Takada, K. and M. Fujino (1987) Studies of $F_{1}$ seed production in the lettuce. I. Heterosis in the $\mathrm{F}_{1}$ lettuce plants produced by crossing a male-sterile line. J. Japan Soc. Hort. Sci. 56 (suppl. 1): 208-209 (in Japanese).

Thompson, R. C. (1933) Natural cross-pollination in lettuce. Proc. Am. Soc. Hort. Sci. 30: 545-547.

Thompson, R. C., T. W. Whitaker, G. W. Bohn and C. W. van Horn (1958) Natural cross-pollination in lettuce. Proc. Am. Soc. Hort. Sci. 72: 403-409.

Thorp, R. W. (1979) Structural, behavioral, and physiological adaptations of bees (Apoidea) for collecting pollen. Ann. Missouri Bot. Gard. 66: 788-812.

Watts, L. E. (1958) Natural cross-pollination in lettuce, Lactuca sativa L. Nature (London) 181: 1084.

Wcislo, W. T. and J. H. Cane (1996) Floral resource utilization by solitary bees (Hymenoptera: Apoidea) and exploitation of their stored foods by natural enemies. Annu. Rev. Entomol. 41: 257-286.

Westerkamp, C. and G. Gottsberger (2000) Diversity pays in crop pollination. Crop Sci. 40: 1209-1222. 